\title{
DEVELOPMENT OF RESOURCE-BASED TECHNOLOGY FOR PRODUCTION OF BLUE VITRIOL FROM INDUSTRIAL PRODUCTS
}

\author{
Sokhibjon T. MATKARIMOV, Malika S. SAIDOVA, Dildora E. ARIBDJONOVA, \\ Saodat B. MIRZAJONOVA, Tursinoy P. KARIMOVA, Nigora K. BAKHODIROVA \\ Department of Mining and Metallurgy, Tashkent State Technical University named after Islam Karimov, \\ Tashkent, Uzbekistan, sohibtm@gmail.com
}

https://doi.org/10.37904/metal.2021.4254

\begin{abstract}
The article considers the possibility of obtaining blue vitriol, where electrolytes, solutions from dehumidification of sludge, washing waters of cuprous production, condensates, and copper granules are used as initial process materials. Possibilities of solubility of charge components using different solvents are considered. An experimental study determined the most optimal indicator of the leaching method using resource-saving technology.
\end{abstract}

Keywords: Blue vitriol, electrolytic copper, solid solution, resource-saving technology

\section{INTRODUCTION}

There is a great demand for blue vitriol in agriculture, which is used as a microenvironment and for the destruction of various insects and the disinfection of drinking water. In the republic, the copper block is produced by the JSC "Almalyk Mining and Metallurgical Complex" (AMMC) (Uzbekistan). Copper block production is an integral of the process flow chart of copper electrolytic refining. Reusing electrolytes, it is possible to carry out the necessary control of the electrolyte composition in the cathode section, both in terms of copper content and in terms of harmful impurities content, thereby ensuring the release of high-quality cathodes [1].

Proper control of the electrolyte composition allows obtaining a smooth surface of the cathodes, which leads to a decrease in electric power consumption and an increase in the current utilization factor.

The constant composition of the electrolyte within the technological norm is achieved:

1) Production of daily chemical analysis of electrolytes for copper and sulphuric acid content, other components for chlorine ions.

2) Due to transfer of part of electrolyte to domed section.

During the processing of electrolyte into copper cuprous, contaminated mother liquors of the third crystallization of cuprous are simultaneously disposed of, as a result of which non-standard products are obtained: electrolyte copper, aqueous copper-nickel salts. Substandard electrolyte copper is sent for remelting to the anode section of copper smelting plant, and salts, semi-products of production are sold to interested organizations [2].

\section{OBJECTS AND METHODS OF RESEARCH}

In the production of copper cuprous, the following are used as initial process materials: electrolyte of the cathode section, solutions from dehumidification of sludge, washing waters of cuprous production, condensate 
and copper granules. Copper pellets are consumed to neutralize sulphuric acid containing the electrolyte to be processed.

Copper block production includes the following technological processes:

- neutralization of electrolyte and circulating solutions with granular copper,

- purification of neutralized solutions from iron and arsenic,

- separation of neutralized, mother and return solutions [3],

- crystallization of copper cuprous to obtain commercial products.

As can be seen from the above, the production of blue vitriol is a labor-intensive and expensive process since anode scrap, or copper granules, are used in neutralizing recycled electrolytes. The reaction is as follows (Equation 1):

$2 \mathrm{Cu}+2 \mathrm{H}_{2} \mathrm{SO}_{4}+\mathrm{O}_{2}=2 \mathrm{CuSO}_{4}+2 \mathrm{H}_{2} \mathrm{O}[1]$

World practice shows that it is copper granules that are used to neutralize the acid. This is an expensive material that increases the cost of cuprous and reduces its competitiveness globally.

In this article, the study results in which we conducted the opportunity to replace copper pellets with coppersmelting dust. Using the results of scientific research work in practice will make it possible to reduce the cost of the obtained blue vitriol and use technological waste [4].

In this regard, the topic of our research work is devoted to the production of blue vitriol using man-made formations - copper-smelting dust instead of expensive copper granules is undoubtedly very relevant.

The study on the use of copper smelting dust as neutralization of spent electrolytes requires solving the following task [5-7]:

- study of the chemical and particle size distribution of copper-smelting dust,

- study of the solubility of components of dust-containing smelting in various solvents,

- selection of optimal condition for leaching of copper-smelting production dust.

To fulfil the task, the object of the study used oxygen-suspended smelting of copper concentrates of the copper smelting plant, AMMC, since when the copper charge is smelted in a suspended state in an flash smelting, a considerable amount of dust is released by process gases ( $15-20 \%$ of the total mass of the processed charge), which is captured in various dust-cleaning.

Tables 1 and 2 show the chemical and particle size distribution of flash smelting dust.

Table 1 Chemical composition of flash smelting dust (wt\%)

\begin{tabular}{|c|c|c|c|c|c|c|c|}
\hline & $\mathbf{C u}$ & $\mathbf{P b}$ & $\mathrm{Zn}$ & $\mathrm{S}_{\text {total }}$ & $\mathrm{SiO}_{2}$ & $\mathrm{Al}_{2} \mathrm{O}_{4}$ & $\mathbf{F e}$ \\
\hline Dry charge: & 17.2 & 0.38 & 0.34 & 32.0 & 10.6 & 2.2 & 28.9 \\
\hline Dust: & & & & & & & \\
\hline Recovery boiler & 19.8 & 1.52 & 1.51 & 10.2 & 4.0 & 1.5 & 26.2 \\
\hline Inertial dust collector & 20.8 & 2.51 & 0.92 & 12.5 & 4.3 & 1.6 & 18.1 \\
\hline Cyclones & 20.6 & 2.10 & 1.37 & 11.2 & 4.4 & 1.9 & 21.9 \\
\hline Electro filters & 19.7 & 1.63 & 1.04 & 12.4 & 3.6 & 2.1 & 21.1 \\
\hline
\end{tabular}

As can be seen from Table 1 in the dust in the flash smelting complex with copper content is high (19.7-20.8 wt\%), more than in the original product. In addition, dust contains several components such as lead, zinc, iron, 
and others. Copper and other dust components are oxides, sulphates, and sulphides with good solubility in water and electrolytes.

It can be seen from Table 2 that the particle size distribution of dust in all units of the dust treatment facilities of the flesh smelting complex in terms of size meets the technological requirements of leaching.

The complexity of the phase composition of flash smelting dust of copper sulphide concentrates and the limited research on their processing led to a cycle of experiments on leaching dust with various reagents: $\mathrm{H}_{2} \mathrm{SO}_{4}$, a mixture of $\mathrm{H}_{2} \mathrm{O}+\mathrm{H}_{2} \mathrm{O}_{2}, \mathrm{CuSO}_{4}+\mathrm{H}_{2} \mathrm{SO}_{4}$, and spent copper electrolytes.

Table 2 Particle size distribution of flash smelting dust (\%)

\begin{tabular}{|c|c|c|c|c|c|c|c|c|}
\hline Fraction $(\mu \mathrm{m})$ & \multicolumn{2}{|c|}{ Recovery boiler } & \multicolumn{2}{|c|}{ Inertial dust collector } & \multicolumn{2}{c|}{ Cyclones } & \multicolumn{2}{c|}{ Electro filters } \\
\hline & Distribution & $\begin{array}{c}\text { Dust } \\
\text { out }\end{array}$ & Distribution & $\begin{array}{c}\text { Dust } \\
\text { out }\end{array}$ & Distribution & $\begin{array}{c}\text { Dust } \\
\text { out }\end{array}$ & Distribution & $\begin{array}{c}\text { Dust } \\
\text { out }\end{array}$ \\
\hline$>60$ & 7.5 & 0.24 & 0 & 0 & 0 & 0 & 0 & 0 \\
\hline $60 \div 40$ & 33.0 & 1.07 & 16.0 & 0.25 & 0 & 0 & 0 & 0 \\
\hline $40 \div 25$ & 23.0 & 0.75 & 20.0 & 0.32 & 21.5 & 0.26 & 0 & 0 \\
\hline $25 \div 18$ & 10.0 & 0.33 & 9.0 & 0.14 & 23.5 & 0.28 & 17.5 & 0.41 \\
\hline $18 \div 10$ & 13.0 & 0.42 & 27.5 & 0.43 & 27.5 & 0.33 & 43.5 & 1.00 \\
\hline$<10$ & 6.0 & 0.20 & 12.5 & 0.19 & 11.5 & 0.14 & 17.5 & 0.40 \\
\hline Total: & 100.0 & 3.25 & 100.0 & 1.56 & 100.0 & 1.20 & 100.0 & 2.31 \\
\hline
\end{tabular}

\section{RESULTS AND DISCUSSION}

The experiments were carried out in a glass flask, on a magnetic agitator with heating, and equipped with a reflux condenser to prevent evaporation of the solution.

A study of the solubility of the main components of flesh smelting dust was studied depending on the concentration of the solvent, on the pulp, on the temperature, and the duration of the process.

Sulphuric acid leaching was carried out with the use of acid with a concentration of the $20 \%$ during two hours at a temperature of $96-98{ }^{\circ} \mathrm{C}$, liquid-to-solid ratio $(\mathrm{L} / \mathrm{S})=1: 3$. It was noted that elemental sulphur was formed during the leaching process, sublimated on the hard part of the reverse cooler. This dust leaching process is of great importance in the production of elemental sulphur. The results of the study are shown in Table 3.

Table 3 Results of sulphuric acid leaching of dust from electro filters Copper flash smelting (dust class 2500 $50 \mu \mathrm{m}), \mathrm{d}$ - density

\begin{tabular}{|c|c|c|c|c|c|c|c|c|c|c|}
\hline \multicolumn{4}{|c|}{ Process factor } & \multirow{2}{*}{$\begin{array}{l}\text { Yield dry } \\
\text { residue(\%) }\end{array}$} & \multicolumn{2}{|c|}{$\begin{array}{c}\text { Filtrate } \\
\text { characteristic }\end{array}$} & \multicolumn{4}{|c|}{ Solid residue content (wt\%) } \\
\hline$T\left({ }^{\circ} \mathrm{C}\right)$ & $\begin{array}{c}\text { time } \\
\text { (hour) }\end{array}$ & L/S & $\begin{array}{l}\mathrm{H}_{2} \mathrm{SO}_{4} \\
\left(\mathrm{~g} / \mathrm{cm}^{3}\right)\end{array}$ & & $\mathrm{pH}$ & $\boldsymbol{d}\left(\mathrm{g} / \mathrm{cm}^{3}\right)$ & $\mathrm{Cu}$ & Fetotal & $\mathrm{Pb}$ & As \\
\hline 35 & 1 & $1: 3$ & 1.4 & 44.8 & 0.24 & 1.270 & 11.8 & 28.62 & 9.0 & 0.35 \\
\hline 98 & 1 & $1: 3$ & 1.4 & 31.6 & 0.34 & 1.320 & 7.2 & 23.45 & 14.4 & 0.22 \\
\hline 98 & 2 & $1: 3$ & 1.4 & 30.6 & 0.06 & 1.315 & 6.65 & 22.75 & 14.8 & 0.18 \\
\hline 98 & 2 & $1: 3$ & 2.0 & 25.0 & -0.09 & 1.372 & 5.0 & 16.75 & 19.2 & 0.21 \\
\hline
\end{tabular}


Table 4 Degree of recovery of main components into solution

\begin{tabular}{|c|c|c|c|c|c|c|c|c|c|c|c|}
\hline \multicolumn{4}{|c|}{ Process factor } & \multicolumn{6}{c|}{ Recovery of major components into solution (wt\%) } \\
\hline $\boldsymbol{t}\left({ }^{\circ} \mathrm{C}\right)$ & time $(\mathrm{h})$ & $\mathbf{L} / \mathbf{S}$ & $\begin{array}{c}\mathbf{H}_{2} \mathbf{S O}_{4} \\
\left(\mathrm{~g} / \mathrm{cm}^{3}\right)\end{array}$ & $\mathbf{S b}$ & $\mathbf{Z n}$ & $\mathbf{C u}$ & $\mathbf{F} \mathbf{t}_{\text {total }}$ & $\mathbf{P b}$ & As & Sb & $\mathbf{Z n}$ \\
\hline 35 & 1 & $1: 3$ & 1.4 & 0.32 & 1.90 & 74.8 & 28.8 & 13.6 & 79.4 & 20.5 & 22.8 \\
\hline 98 & 1 & $1: 3$ & 1.4 & 0.34 & 1.50 & 88.6 & 58.8 & 9.0 & 90.9 & 40.2 & 56.9 \\
\hline 98 & 2 & $1: 3$ & 1.4 & 0.20 & 1.40 & 89.9 & 61.4 & 9.3 & 92.7 & 66.0 & 61.0 \\
\hline 98 & 2 & $1: 3$ & 2.0 & 0.26 & 0.90 & 94.8 & 76.7 & 4.0 & 94.3 & 64.0 & 79.6 \\
\hline
\end{tabular}

Salt leaching with a copper sulphate solution is based on the known fact that some non-ferrous metal sulphides can be dissolved in bivalent copper salts. The formula (Equation 2 ) generally describes the process:

$2 \mathrm{MeS}+2 \mathrm{Cu}^{2+}+\mathrm{O} 2=\mathrm{Me}^{2+}+2 \mathrm{Cu}++2 \mathrm{SO}$ [2]

The condition for the development of the process is the presence of sulphides in the raw materials. The solubility of dust in copper sulphate is $36-37 \%$, indicating a small content of sulphide forms of non-ferrous metals, particularly copper. Acidification of sulphate solutions leads to an increase in the completeness of the recovery of $\mathrm{Cu}, \mathrm{Zn}$, and $\mathrm{Fe}$, and cakes are enriched with noble metals and sulphur elements.

Leaching with a copper electrolyte containing up to $170 \mathrm{~g} / / \mathrm{H}_{2} \mathrm{SO}_{4}$ at a $95-98^{\circ} \mathrm{C}$ temperature, $\mathrm{L} / \mathrm{S}=1: 3$ during 2 hours leads to dust solubility by $61-62 \%$, the transition of copper from dust to solution was $95-96 \%$.

Table 5 Results of flash smelting dust leaching with various reagents

\begin{tabular}{|c|c|c|c|c|c|c|c|c|c|c|}
\hline \multirow{2}{*}{ Reagent } & \multicolumn{9}{|c|}{ Dust component } & \multirow{2}{*}{$\begin{array}{l}\text { Cake yield } \\
\text { of dust }(\mathrm{wt} \%)\end{array}$} \\
\hline & As & $\mathbf{S b}$ & $\mathrm{Pb}$ & $\mathrm{Zn}$ & $\mathrm{Cu}$ & $\mathrm{Fe}$ & $\mathbf{s}$ & $\mathrm{Au}$ & $\mathrm{Ag}$ & \\
\hline & \multicolumn{7}{|c|}{ Composition of solutions before leaching $(\mathrm{g} / \mathrm{l})$} & \multicolumn{2}{|c|}{$\left(\mathrm{mg} / / \cdot 10^{-2}\right)$} & \\
\hline $\mathrm{H}_{2} \mathrm{SO}_{4}$ & 1.30 & 1.14 & 0.775 & 5.41 & 77.5 & 65.6 & 27.1 & 0 & 2.5 & - \\
\hline $\mathrm{CuSO}_{4}+\mathrm{H}_{2} \mathrm{SO}_{4}$ & 1.31 & 1.13 & 0.405 & 5.31 & 76.9 & 64.1 & 27.0 & 0 & 1.84 & - \\
\hline Copper electrolyte & 1.25 & 1.01 & 0.610 & 3.66 & 66.3 & 44.4 & 26.7 & 0 & 1.71 & - \\
\hline \multirow[t]{2}{*}{$\mathrm{H}_{2} \mathrm{O}_{2}$} & 0.39 & 1.12 & 0.17 & 2.33 & 40.9 & 36.3 & 19.5 & 0 & 0 & - \\
\hline & \multicolumn{7}{|c|}{ Composition of solutions after leaching $(\mathrm{g} / \mathrm{l})$} & \multicolumn{2}{|c|}{$\left(\mathrm{mg} / \cdot \cdot 10^{-2}\right)$} & \\
\hline $\mathrm{H}_{2} \mathrm{SO}_{4}$ & 0.12 & 0.10 & 24.24 & 0.41 & 5.37 & 5.58 & 12.1 & 91.0 & 560 & 21.4 \\
\hline $\mathrm{CuSO}_{4}+\mathrm{H}_{2} \mathrm{SO}_{4}$ & 0.10 & 0.12 & 23.82 & 0.57 & 6.19 & 7.81 & 11.6 & 86.0 & 604 & 21.6 \\
\hline Copper electrolyte & 0.12 & 0.176 & 14.5 & 1.9 & 13.5 & 23.15 & 7.19 & 49.0 & 375 & 38.2 \\
\hline $\mathrm{H}_{2} \mathrm{O}_{2}$ & 0.55 & 0.02 & 12.43 & 1.65 & 16.64 & 13.07 & 4.89 & 33.8 & 373 & 55.0 \\
\hline \multicolumn{11}{|c|}{ Degree of extraction of main dust components into solution (\%) } \\
\hline $\mathrm{H}_{2} \mathrm{SO}_{4}$ & 95.0 & 93.9 & 36.3 & 95.0 & 96.5 & 92.1 & 80.0 & 0 & 44.2 & - \\
\hline $\mathrm{CuSO}_{4}+\mathrm{H}_{2} \mathrm{SO}_{4}$ & 95.5 & 94.3 & 18.7 & 94.0 & 95.8 & 90.1 & 73.6 & 0 & 32.5 & - \\
\hline Copper electrolyte & 90.1 & 84.5 & 1.96 & 64.8 & 82.4 & 62.3 & 78.1 & 0 & 30.3 & - \\
\hline Sulphide-alkaline electrolyte & 79.0 & 0 & 2.2 & 8.5 & 58.9 & 14.8 & 90.7 & 0 & 13.3 & - \\
\hline $\mathrm{H}_{2} \mathrm{O}_{2}$ & 40.0 & 97.5 & 11.1 & 55.7 & 68.7 & 72.2 & 78,4 & 0 & 0 & - \\
\hline
\end{tabular}

Table shows these results of flash smelting dust leaching with various reagents.

The results obtained and their discussion. Leaching with a hydrogen peroxide solution was studied under agitation conditions at a temperature of $95 \pm 20^{\circ} \mathrm{C}$. The pulp was kept in the reactor for two hours at $\mathrm{L} / \mathrm{S}=$ 
1:3-4. Due to the tremendous exothermic nature of the process, intense boiling of pulp was noted, which should be borne in mind when loading a reagent, exceptionally concentrated $25-30 \%$. Under this condition, the dust solubility was $45-46 \%$, which cannot be said to be satisfactory. The complexity of the process and the comparatively high cost of $\mathrm{H}_{2} \mathrm{O}_{2}$ also do not allow to recommend this reagent for leaching.

\section{CONCLUSION}

As can be seen from Summary Table 5, the high recovery rate of copper and other major dust components corresponds to the leaching of dust in the sulphuric acid solution (the copper recovery rate is $96.5 \%$ ); these data indicate that dust in the OFF furnace is more suitable for neutralizing spent copper electrolytes.

Output. According to the results obtained from the study of the possibility of using man-made wastes AMMC, the following conclusions can be drawn.

The chemical, mineralogical, phase, and granulometric compositions of dust and dust treatment facilities of the AMMC were studied. It was established that in the production of copper dust, instead of copper granules used to neutralize free sulphuric acid, copper smelting dust can be used.

The degree of solubility of the charge components with various solvents was investigated, and the most optimal leaching process parameters were determined.

The technology we offer will significantly reduce the cost of copper cupronickel and increase its competitiveness globally.

Processing of dust in a separate cycle will reduce the ballast turnover of dust into the process of the OFF furnace - electro filter recovery boiler - OFF furnace and increase the latter's efficiency in charge by $10-15 \%$ with simultaneous increase of process autogenicity.

\section{REFERENCE}

[1] KHUDYAKOV, I.F., TIKHONOV, A.I. The technology of secondary non-ferrous metals. Moscow: Metallurgy. 2016, p. 280.

[2] YUSUPHODJAYEV, A. ARIBDJONOVAD, E. Processing of steel. Tashkent: TashSTU, 2016, p. 132.

[3] SANAKULOV, K.S. Scientific and technical basis for processing waste from mining and metallurgical production. Tashkent: Fan, 2009, p. 404.

[4] MATKARIMOV, S.T., YUSUPKHODJAEV, A.A., KHOJIEV, S.T., BERDIYAROV, B.T., MATKARIMOV, Z. Technology for the complex recycling slags of copper production. Journal of Critical Reviews. [online]. 2020, vol. 7, no. 5, pp. 214-220. Available from: https://doi.org/10.31838/JCR.07.05.38.

[5] VANYUKOV A.V., ZAYTSEV, V.Ya. Theory of pyrometallurgical processes. Moscow: Metallurgy, 2003, p. 504.

[6] MATKARIMOV, S.T., NOSIRKHUDJAYEV, S.Q.U., OCHILDIYEV, Q.T., NURALIYEV, O.U.U., KARIMDJONOV, B.R. Technological processes of receiving metals in the conditions of moderate temperatures. International Journal of Innovative Technology and Exploring Engineering. [online]. 2019, vol. 8, no. 12, pp. 1826-1828. Available from: https://doi.org/10.35940/ijitee.L2856.1081219.

[7] ARKHIPOV, V.S., SMOLYANINOV, S.I. Influence of reactionary ability of carbon on hematite restoration speed. Izv. Higher education institutions. Ferrous Metallurgy. 1989. № 1, pp. 10-13. 